\title{
Methylation of SOX1 and VIM promoters in serum as potential biomarkers for hepatocellular carcinoma
}

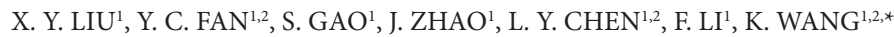 \\ ${ }^{1}$ Department of Hepatology, Qilu Hospital of Shandong University, Jinan, Shandong, China; ${ }^{2}$ Institute of Hepatology, Shandong University, Jinan, \\ Shandong, China \\ ${ }^{*}$ Correspondence: wangdoc876@126.com
}

Received September 02, 2016 / Accepted February 14, 2017

\begin{abstract}
Aberrant methylation of tumor-related genes has been identified as a promising biomarker for hepatocellular carcinoma (HCC). This study aimed to investigate the diagnostic value of SRY (sex determining region Y)-box 1 (SOX1) and Vimentin (VIM) promoter methylation for HCC. The study included 360 subjects, 240 patients with HCC, 29 with liver cirrhosis (LC), 66 with chronic hepatitis B (CHB) and 25 healthy controls (HCs). The methylation status of SOX1 and VIM promoters in the serum was detected by methylation-specific polymerase chain reaction (MSP). The methylation frequencies of SOX1 and VIM promoters in HCC patients were significantly higher than those in LC $(p<0.001$ and $p<0.001), \mathrm{CHB}(p<0.001$ and $p<0.001)$ and $\mathrm{HC}(p<0.001$ and $p<0.001)$ subjects. Furthermore, hypermethylation of SOX1 and VIM promoters were found in patients with advanced TNM stage (III-IV) and larger tumor size $(\geq 5 \mathrm{~cm})$ compared with early stage (I-II) ( $p<0.001$ and $p=0.004)$ patients with smaller tumor size $(<3 \mathrm{~cm})(p=0.018$ and $p=0.001)$. Moreover, the VIM promoter methylation frequency was higher in patients with portal vein tumor thrombosis (PVTT) $(p=0.006)$ and vascular invasion $(p=0.003)$. In addition, the combination of $\alpha$-fetoprotein $(\geq 20 \mathrm{ng} / \mathrm{ml}$ ) with SOX1 and VIM promoter methylation significantly improved their diagnostic value. In conclusions, aberrant methylation of SOX1 and VIM promoters may be potential biomarkers for noninvasive detection of HCC and HCC metastasis.
\end{abstract}

Key words: methylation, SOX1, VIM, hepatocellular carcinoma

Hepatocellular carcinoma (HCC) ranks as the fifth most common cancer in men and the seventh in women worldwide. It is the third most frequent cause of cancer-related mortality. In Asia and Africa, the incidence of HCC is higher than that in Southern Europe, and incidence is the lowest in most highincome countries [1]. Hepatitis B virus (HBV) and hepatitis $\mathrm{C}$ virus (HCV) infections are risk factors for HCC [2]. Early diagnosis of $\mathrm{HCC}$ is a prerequisite for any curative therapy [3]. Recently, diagnostic procedures have been greatly improved. Clinically, detection of HCC is based on serum a-fetoprotein (AFP), biopsy of the lesion and various imaging technologies, including ultrasonography, multi-detector computed tomography and diffusion-weighted magnetic resonance imaging. However, certain limitations remain in these techniques for HCC surveillance and diagnosis [4]. AFP, a specific tumor marker, has been used for clinical diagnosis of HCC for more than 30 years. However, AFP has also been found in some benign cases of liver disease, and more than $30 \%$ of HCC patients are AFP negative. Therefore, evaluation of AFP alone can lead to misdiagnosis and missed diagnoses [5]. Imaging technologies depend on examiner expertise, patient data, the presence of liver cirrhosis and tumor size, and smaller tumors are difficult to detect. Biopsy of the lesion is an invasive procedure. Thus, the development of new biomarkers is of great importance for improving the diagnosis of early-stage HCC.

Biomarkers are biological characteristics that are widely used to forecast risk, diagnose diseases and predict prognosis. They are easily and objectively measured at any stage of a disease [6-8]. Circulating cell-free tumor DNA (ctDNA) in the blood of patients with cancer can be detected as a biological biomarker [9]. It offers a simple and noninvasive method to diagnose and prognose carcinoma [10]. Epigenetic alterations play an important role in the initiation and progression of human cancer. The most common epigenetic change in tumors is aberrant DNA methylation in the promoter regions of genes, which lead to silencing of tumor-suppressor genes. Numerous 
studies have confirmed that using DNA methylation changes as biomarkers for carcinoma is useful for early detection of cancer, including HCC [11]. For example, aberrant methylation of serum ELF, RASSF1A, GSTP1, APC, SFRP1, LINE-1, $G R A$ has been shown to be useful as biomarkers for assessing the risk of HCC [12-16]. Abnormal hypermethylation of a CpG island in different stages of tumorigenesis is a dysfunction of tumor suppressor genes (TSGs) [17-19]. Hypermethylation of gene promoters could be markers for HCC in early or late events $[20,21]$.

SRY (sex determining region Y)-box 1 (SOX1) is a member of the SRY-box (SOX) family of proteins and plays an important role during embryonic and postnatal development [22]. It encodes a transcription factor implicated in the regulation of embryonic development and the determination of cell fate [23]. SOX1 is frequently downregulated through promoter hypermethylation in HCC cell lines and tumor tissues. Ectopic expression of SOX1 leads to significant repression of HCC growth by interfering with Wnt $/ \beta$-catenin signaling. Therefore, SOX1 is an important tumor suppressor of HCC [24]. Vimentin (VIM) belongs to the family of intermediate filaments, which are specifically found in connective tissues [25]. The VIM gene encodes Vimentin and plays an important role in various biological processes, such as maintaining cell shape and stabilizing cytoskeletal interactions. VIM is also related to cell migration, inflammation and signal transduction [26]. Previous studies have found that aberrant methylation of SOX1 is correlated with

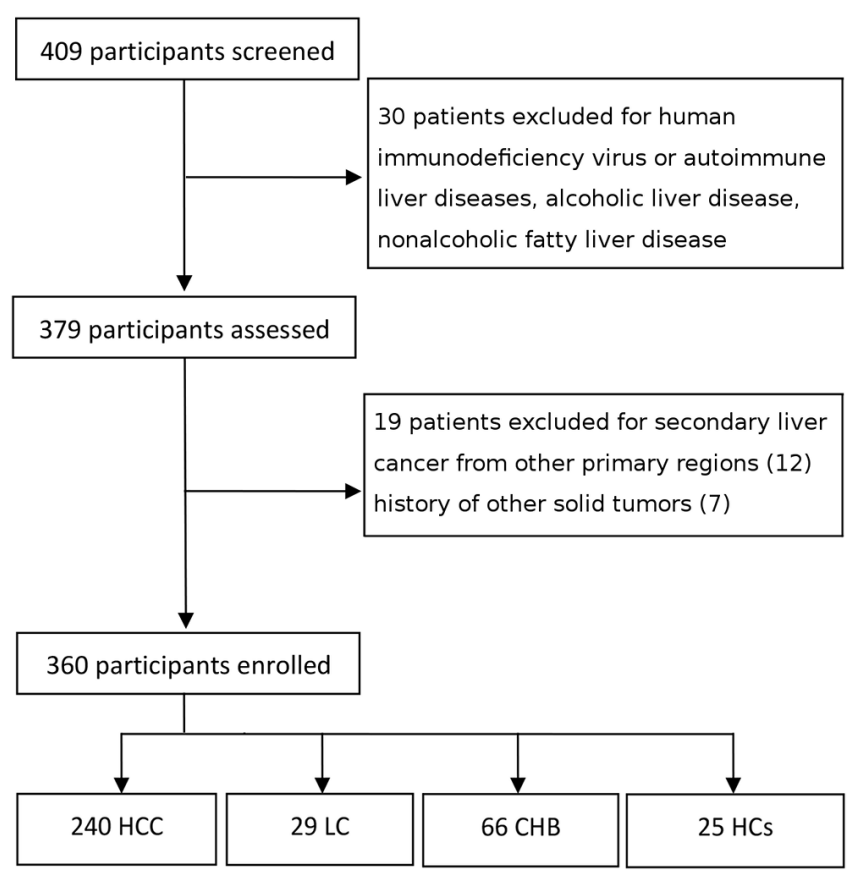

Figure 1. Flowchart depicting the selection process of the participants. HCC: Hepatocellular carcinoma; LC: Liver cirrhosis; CHB: Chronic hepatitis B; HCs: Healthy controls. cervical and non-small cell lung cancer [27, 28], and aberrant methylation of the VIM gene is associated with cervical and pancreatic carcinoma [26, 29]. Serum SOX1 and VIM methylation could be potential predictive biomarkers for ovarian and colorectal cancer [30, 31]. Aberrant methylation of SOX1 and VIM has been detected in HCC tissues $[32,33]$. However, the role of SOX1 and VIM expression in the serum of HCC patients is unclear. Therefore, we chose these two genes and aimed to evaluate the potential value of serum SOX1 and VIM promoter methylation as noninvasive biomarkers for the diagnosis of HCC.

In this study, we used methylation-specific polymerase chain reaction (MSP) to determine the promoter methylation of SOX1 and VIM genes in patients with HCC, CHB, LC and in healthy blood donors. Then, we evaluated the methylation status among them and assessed the diagnostic value for HCC.

\section{Patients and methods}

Study populations. The study enrolled 360 subjects, including 240 patients with HCC, 29 cases with LC, 66 cases with $\mathrm{CHB}$ and $25 \mathrm{HCs}$, at the Department of Hepatology, Qilu Hospital of Shandong University from July 2014 to July 2015. All subjects with HCC were diagnosed according to the criteria of the American Association for The Study of Liver Diseases (AASLD), which was updated in 2010 [34]. The 2009 Edition of AASLD Practice Guidelines were used to diagnose CHB patients in this study [35]. A history of other tumors, human immunodeficiency virus or autoimmune liver diseases, alcoholic liver disease, nonalcoholic fatty liver disease and other causes of chronic liver disease were the exclusion criteria (Figure 1). All patients who agreed to participate in this study signed a written informed consent, and the study protocol was approved by the Ethics Committee of Qilu Hospital. Alanine aminotransferase (ALT), aspartate aminotransferase (AST), total bilirubin (TBIL), albumin (ALB) and prothrombin timeinternational normalized ratio (PT-INR) were measured using a Roche automated biochemical analyzer cobas $\mathrm{c} 311$ (Roche Diagnostic Ltd, Germany). Hepatitis B e antigen (HBeAg) and serum AFP levels were detected with an electrochemiluminescence immunoassay using an automatic analyzer (COBAS e 601, Roche Diagnostics, Mannheim, Germany). AFP concentrations higher than $20 \mathrm{ng} / \mathrm{ml}$ were considered abnormal. Tumor size was determined by computed tomography and is presented as the longest diameter.

Serum DNA extraction and sodium bisulfite modification. DNA was extracted from $400 \mu \mathrm{l}$ of serum with a QIAamp DNA Blood Mini Kit (Qiagen, Mainz, Germany) according to the protocol for DNA purification from blood as recommended by the manufacturer. Then, $200 \mu$ of serum DNA was eluted and stored at $-20^{\circ} \mathrm{C}$ until use. An EZ DNA MethylationGold Kit ${ }^{\mathrm{TM}}$ (Zymo Research, USA) was used to treat $20 \mu \mathrm{l}$ of DNA according to the manufacturer's instructions. Finally, $20 \mu \mathrm{l}$ of modified DNA was obtained as a template for MSP or stored at $-20^{\circ} \mathrm{C}$. 

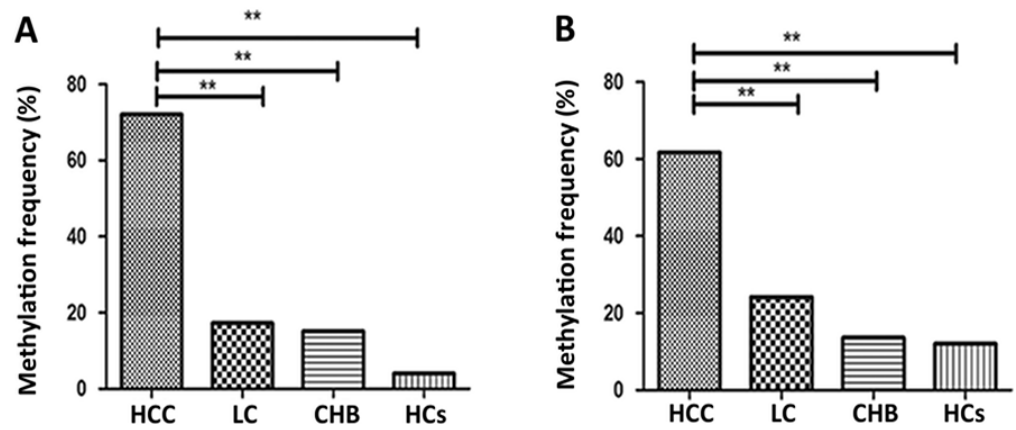

Figure 2. The methylation frequency of the serum SOX1 and VIM promoters in hepatocellular carcinoma (HCC), liver cirrhosis (LC), chronic hepatitis $\mathrm{B}(\mathrm{CHB})$, and healthy control (HC) group. A: Percentage methylation of SOX1; B: Percentage methylation of VIM. ${ }^{\star *} p<0.001$.

Methylation-specific polymerase chain reaction (MSP). Methylated and unmethylated primers of SOX1 and VIM for MSP were used to amplify the bisulfite-modified DNA. The MSP primer sequences were obtained from previous studies $[27,36]$. The expected size of the PCR product of SOX1 was $135 \mathrm{bp}$ and that of VIM was $151 \mathrm{bp}$ (Table 1). Briefly, $12.5 \mu \mathrm{l}$ of Premix Taq (Zymo Research, USA), $10.5 \mu \mathrm{l}$ of nucleasefree water, $0.5 \mu \mathrm{l}$ of each primer and $1 \mu \mathrm{l}$ of bisulfite-treated DNA were combined to a volume of $25 \mu \mathrm{l}$ in the MSP reaction system. The PCR protocol was composed of an initial denaturation step at $95^{\circ} \mathrm{C}$ for $5 \mathrm{~min}$, followed by 45 cycles of denaturation at $95^{\circ} \mathrm{C}$ for $30 \mathrm{~s}$, annealing at $58^{\circ} \mathrm{C}$ for $40 \mathrm{~s}$, and primer extension at $72{ }^{\circ} \mathrm{C}$ for $40 \mathrm{~s}$; finally, an extension step was set at $72{ }^{\circ} \mathrm{C}$ for $10 \mathrm{~min}$. The negative control was water without DNA. A total of $7 \mu \mathrm{l}$ of PCR products were then electrophoresed on a $2 \%$ agarose gel, stained with Gel Red and visualized under UV illumination. According to the guidelines of the MSP procedure, methylation was identified if only the $\mathrm{M}$ band or both the $\mathrm{M}$ and $\mathrm{U}$ bands were positive, while unmethylation was identified if the $\mathrm{U}$ band was positive $[37,38]$.

Statistical analysis. All data were analyzed using SPSS v.20.0 software. The methylation percentage was calculated by the ratio of the methylated number/total number in each group. Chi-square test was used to compare the differences in serum SOX1 and VIM methylation status between different groups. Then, we evaluated the correlation between serum SOX1 and VIM methylation status in HCC patients and their clinicopathological parameters via a chi-square test. Univariate logistic regression was also used to investigate the relationship between clinicopathological parameters and $S O X 1$ and VIM promoter methylation. The $p$ value for entry into the regression model was 0.05 and that for removal was 0.1 . Diagnostic values of SOX1 and VIM methylation and serum AFP level were assessed by the area under the receiver operating characteristic curve (AUC). As to the combination of SOX1 and VIM methylation and AFP, patients with AFP $\geq 20 \mathrm{ng} / \mathrm{ml}$ or methylated SOX1 and VIM were regarded as positive. Patients with AFP $<20 \mathrm{ng} / \mathrm{ml}$ and unmethylated SOX1 and VIM were regarded as negative. Sensitivity, specificity, positive predictive value (PPV) and negative predictive value (NPV) were calculated. The statistical significance was defined as $\mathrm{p}<0.05$.

\section{Results}

Methylation status of SOX1 and VIM in serum. First, we examined the methylation status of the serum SOX1 and VIM promoter in 240 HCC patients, 29 LC patients, 66 $\mathrm{CHB}$ patients and $25 \mathrm{HCs}$. Baseline characteristics of the participants are shown in Table 2. The chi-square test analysis indicated that the percentage of SOX1 promoter methylation was significantly higher in the HCC group $(72.08 \%)$ than in the LC group $(17.24 \%, p<0.001)$, the CHB group $(15.15 \%$, $p<0.001)$ and the HCs $(4.00 \%, p<0.001)$. However, there were no significant differences for SOX1 between the LC group and the CHB group $(p=0.061)$, the $\mathrm{CHB}$ group and the healthy control group $(p=0.057)$, or the LC group and the healthy control group ( $p=0.059$; Figure $2 \mathrm{~A}$ ). The methylation frequency of the VIM promoter was also higher in the HCC group $(61.67 \%)$ than in the LC group $(24.14 \%, p<0.001)$, the CHB group $(13.64 \%, p<0.001)$ and the HCs $(12.00 \%$,

Table 1. Primers of the SOX1 and VIM Gene for MSP

\begin{tabular}{llcc}
\hline Primer & Primer sequence (5'-3') & $\begin{array}{l}\text { Product } \\
\text { size }(\mathrm{bp})\end{array}$ & $\begin{array}{c}\text { Annealing } \\
\text { temp }\left({ }^{\circ} \mathrm{C}\right)\end{array}$ \\
\hline $\begin{array}{l}\text { SOX1 } \\
\mathrm{M}\end{array}$ & $\begin{array}{l}\text { F:CGTTTTTTTTTTTCGTTATTGGC } \\
\text { R:CCTACGCTCGATCCTCAACG }\end{array}$ & 135 & 58 \\
& & & \\
$\mathrm{U}$ & F:TGTTTTTTTTTTTTGTTATTGGTG & 135 & 56 \\
& R:CCTACACTCAATCCTCAACAAC & & \\
VIM & & & \\
& F:GGATTTTTTTGGTTTAGTTTTAGGC & 151 & 58 \\
& R:AACATAATCCCGTTACTTCAACG & & \\
$\mathrm{U}$ & F:ATTTTTTTGGTTTAGTTTTAGGTGG & 151 & 58 \\
& R:ACATAATCCCATTACTTCAACACT & & \\
\hline
\end{tabular}

MSP, methylation-specific polymerase chain reaction $M$, methylated sequence; $\mathrm{U}$, unmethylated sequence; $\mathrm{F}$, forward; $\mathrm{R}$, reverse. 


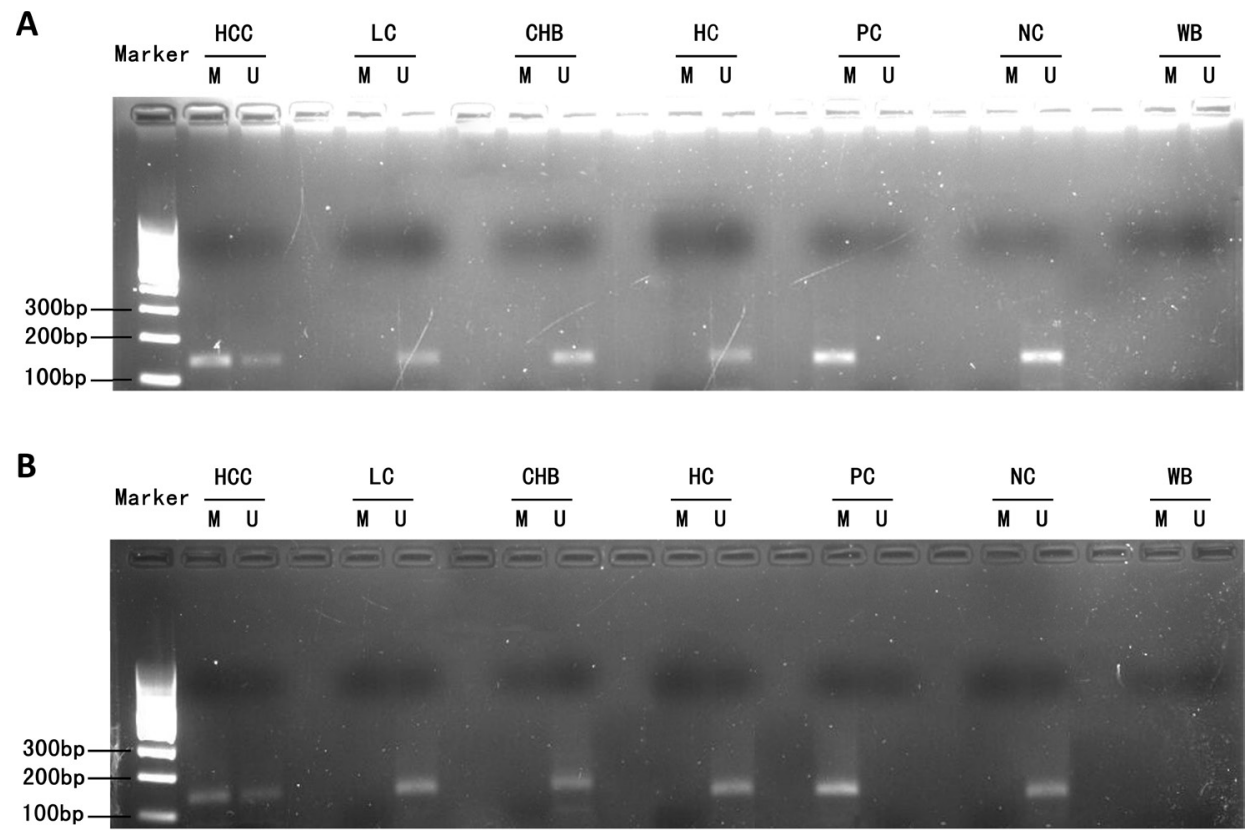

Figure 3. Representative results showing the SOX1 and VIM promoter methylation status identified by MSP in serum samples from hepatocellular carcinoma (HCC) patients, liver cirrhosis (LC) patients, chronic hepatitis B (CHB) patients, and healthy controls (HCs). A: The methylated and unmethylated sequences of SOXI; B: The methylated and unmethylated sequences of VIM. A 100-bp DNA ladder marker was used. M and U indicate the amplified products with primers recognizing methylated and unmethylated sequences, respectively. PC, positive control; NC, negative control; WB, water blank.

$p<0.001)$. Moreover, no significant differences in VIM were found between the LC group and the CHB group $(p=0.083)$, the $\mathrm{CHB}$ group and the healthy control group $(p=0.074)$, or the LC group and the healthy control group $(p=0.052$; Figure 2B). Typical results of MSP for the SOX1 and VIM promoters are presented in Figure 3.
Correlation between SOX1 and VIM promoter methylation and clinicopathological parameters. The association between the methylation status of the SOX1 and VIM promoters and clinicopathological characteristics of HCC patients is shown in Table 3. There was no significant correlation between the methylation status of SOX1 and VIM

Table 2. Baseline Characteristics of the Participants

\begin{tabular}{|c|c|c|c|c|}
\hline Variable & $\begin{array}{l}\text { HCC group } \\
\qquad(\mathrm{n}=240)\end{array}$ & $\begin{array}{l}\text { LC group } \\
\qquad(\mathrm{n}=29)\end{array}$ & $\begin{array}{l}\text { CHB group } \\
(n=66)\end{array}$ & $\begin{array}{l}\text { HCs group } \\
\quad(\mathrm{n}=25)\end{array}$ \\
\hline Age (years) & $57.0(21.0-83.0)$ & $47.0(38.0-50.0)$ & $43.0(18.0-75.0)$ & $28.0(23.0-42.0)$ \\
\hline Gender (M/F) & $178 / 62$ & $15 / 14$ & $39 / 27$ & $10 / 15$ \\
\hline $\operatorname{HBeAg}(+/-)$ & $202 / 38$ & $16 / 13$ & $42 / 24$ & NA \\
\hline $\operatorname{ALT}(\mathrm{U} / \mathrm{I})$ & $80.72(11.00-1762.00)$ & $188.72(85.00-1061.00)$ & $129.44(24-256.00)$ & NA \\
\hline AST (U/I) & $114.22(20.00-1008.00)$ & $154.00(28.00-793.00)$ & $80.86(35.00-200.00)$ & NA \\
\hline TBIL $(\mu \mathrm{mol} / \mathrm{l})$ & $22.83(4.30-47.80)$ & $24.36(17.90-52.20)$ & $24.43(9.90-36.20)$ & NA \\
\hline $\operatorname{ALB}(g / l)$ & $37.45(22.30-204.00)$ & $36.18(28.00-46.00)$ & $35.47(31.00-42.00)$ & NA \\
\hline PT-INR & $1.15(0.93-1.93)$ & $1.35(1.01-1.93)$ & $1.17(1.09-1.25)$ & NA \\
\hline $\operatorname{AFP}(\mathrm{ng} / \mathrm{ml})$ & $621.41(1.44-24200.00)$ & $7.61(2.67-41.80)$ & $15.96(2.50-39.9)$ & NA \\
\hline \multicolumn{5}{|c|}{ Methylation (\%) } \\
\hline SOX1 & 72.08 & 17.24 & 15.15 & 4.00 \\
\hline VIM & 61.67 & 24.14 & 13.64 & 12.00 \\
\hline
\end{tabular}

HCC, hepatocellular carcinoma; CHB,chronic hepatitis B ; LC, liver cirrhosis; HCs, healthy controls ; M, male; F, female; ALT, alanine aminotransferase; AST, aspartate aminotransferase; TBIL, total bilirubin; ALB, albumin; PT-INR, prothrombin time-international normalized ratio; AFP, alpha-fetoprotein; NA, not available 
and patient gender, age, viral infection, smoking status, alcohol use, Child-Pugh stage or Milan standards. We also found that $S O X 1$ promoter methylation was related to the tumor number $(\chi 2=6.107, p=0.013)$, tumor size $(\chi 2=7.986$, $p=0.018)$ and TNM stage $(\chi 2=12.458, p=0.001)$. The VIM promoter had a higher methylation frequency in patients with portal vein tumor thrombosis $(\chi 2=7.528, p=0.006)$, tumor number $(\chi 2=9.997, p=0.002)$, tumor size $(\chi 2=19.451$, $p=0.001)$, TNM stage $(\chi 2=8.291, p=0.004)$ and vascular invasion $(\chi 2=8.832, p=0.003)$. Furthermore, univariate logistic regression was used to analyze the correlation between SOX1 and VIM promoter methylation and the characteristics of HCC (Tables 4 and 5). The serum SOX1 promoter methylation was more frequent in HCC patients with multiple tumors $(\mathrm{OR}=0.208, p<0.001)$ and TNM stage
(III-IV) $(\mathrm{OR}=4.987, p<0.001)$. VIM promoter methylation was highly correlated with PVTT $(\mathrm{OR}=0.006, p<0.001)$, TNM stage (III-IV) $(\mathrm{OR}=3.978, p<0.001)$, tumor size $>5 \mathrm{~cm}$ $(\mathrm{OR}=2.340, p=0.037)$ and vascular invasion $(\mathrm{OR}=33.681$, $p<0.001)$.

Diagnostic value of serum concentrations of AFP and promoter-methylated SOX1 and VIM in HCC. To discriminate HCC from LC and CHB, the sensitivity is $72.08 \%$ for SOX1 and $61.67 \%$ for VIM, higher than AFP alone (56.67\%, $\chi 2=12.436, p<0.001 ; \chi 2=1.242, p=0.265)$. When we combined SOX1 and VIM promoter methylation, higher sensitivity (82.50\%) but lower specificity (78.95\%) for discriminating HCC from CHB and LC was found, as shown in Table 6. Then, we compared the diagnostic value of AFP combined with SOX1 and VIM methylation, and the two methods are presented in

Table 3. Correlations Between SOX1 and VIM Promoter Methylation Status and Clinicopathological Characteristics of the HCC Patients

\begin{tabular}{|c|c|c|c|c|c|c|c|c|}
\hline \multirow{2}{*}{ Parameters } & \multicolumn{2}{|c|}{ SOX1 } & \multirow{2}{*}{$x^{2}$} & \multirow{2}{*}{$\begin{array}{c}p \\
\text { value }\end{array}$} & \multicolumn{2}{|c|}{ VIM } & \multirow{2}{*}{$x^{2}$} & \multirow{2}{*}{$\begin{array}{c}p \\
\text { value }\end{array}$} \\
\hline & Methylated & Unmethylated & & & Methylated & Unmethylated & & \\
\hline \multicolumn{9}{|l|}{ Age } \\
\hline$<55$ & 82 & 28 & \multirow[t]{2}{*}{0.612} & \multirow[t]{2}{*}{0.434} & 71 & 39 & \multirow[t]{2}{*}{0.712} & \multirow[t]{2}{*}{0.399} \\
\hline$\geq 55$ & 91 & 39 & & & 77 & 53 & & \\
\hline Gender (M/F) & $127 / 46$ & $51 / 16$ & 0.185 & 0.667 & $112 / 36$ & $66 / 26$ & 0.459 & 0.498 \\
\hline \multicolumn{9}{|l|}{ Viral infection } \\
\hline $\mathrm{HBV}$ & 157 & 62 & \multirow{4}{*}{1.199} & \multirow{4}{*}{0.753} & 131 & 88 & \multirow{4}{*}{4.225} & \multirow{4}{*}{0.238} \\
\hline $\mathrm{HCV}$ & 9 & 3 & & & 10 & 2 & & \\
\hline $\mathrm{HBV}$ and $\mathrm{HCV}$ & 1 & 1 & & & 2 & 0 & & \\
\hline Non HBV,non HCB & 6 & 1 & & & 5 & 2 & & \\
\hline Smoking(+/-) & $107 / 66$ & $39 / 28$ & 0.269 & 0.604 & $95 / 53$ & $51 / 41$ & 1.825 & 0.177 \\
\hline Alcohol (+/-) & $119 / 54$ & $45 / 22$ & 0.059 & 0.809 & $107 / 41$ & $57 / 35$ & 2.804 & 0.094 \\
\hline \multicolumn{9}{|l|}{ Child - Pugh } \\
\hline A & 39 & 20 & \multirow{3}{*}{3.665} & \multirow{3}{*}{0.160} & 41 & 18 & \multirow{3}{*}{3.035} & \multirow{3}{*}{0.362} \\
\hline B & 71 & 31 & & & 60 & 42 & & \\
\hline $\mathrm{C}$ & 63 & 16 & & & 47 & 32 & & \\
\hline \multicolumn{9}{|l|}{$\operatorname{AFP}(\mathrm{ng} / \mathrm{ml})$} \\
\hline$<20$ & 79 & 25 & \multirow{2}{*}{1.372} & \multirow{2}{*}{0.242} & 65 & 39 & \multirow[t]{2}{*}{0.003} & \multirow{2}{*}{0.956} \\
\hline$\geq 20$ & 94 & 42 & & & 83 & 53 & & \\
\hline Size $(\mathrm{cm})$ & & & & & & & & \\
\hline$<3$ & 35 & 19 & & & 24 & 30 & & \\
\hline $3-5$ & 49 & 27 & 7.986 & 0.018 & 40 & 36 & 19.451 & 0.001 \\
\hline$\geq 5$ & 89 & 21 & & & 84 & 26 & & \\
\hline $\operatorname{PVTT}(+/-)$ & $17 / 156$ & $7 / 60$ & 0.021 & 0.886 & $21 / 127$ & $3 / 89$ & 7.528 & 0.006 \\
\hline TNM stage & & & & & & & & \\
\hline I/II & 53 & 37 & 12.458 & 0.001 & 45 & 45 & 8.291 & 0.004 \\
\hline III/IV & 120 & 30 & & & 103 & 47 & & \\
\hline Milan standard & & & & & & & & \\
\hline Yes & 79 & 38 & 2.361 & 0.124 & 78 & 39 & 2.414 & 0.120 \\
\hline No & 94 & 29 & & & 70 & 53 & & \\
\hline Tumor multiplicity & & & & & & & & \\
\hline single & 117 & 56 & 6.107 & 0.013 & 96 & 77 & 9.997 & 0.002 \\
\hline multiple & 56 & 11 & & & 52 & 15 & & \\
\hline Vascular invasion or metastasis $(+/-)$ & $52 / 121$ & $19 / 48$ & 0.067 & 0.796 & $54 / 94$ & $17 / 75$ & 8.832 & 0.003 \\
\hline
\end{tabular}

M, male; F, female; TNM, tumor node metastasis; PVTT, portal vein tumor thrombus 


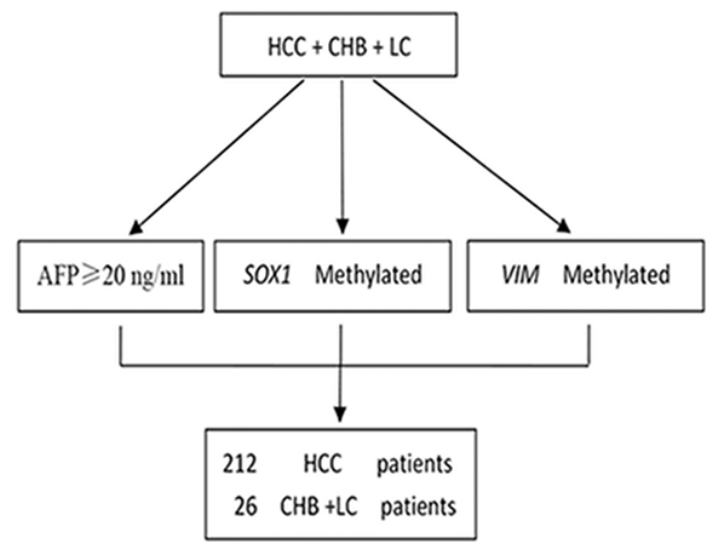

Method I

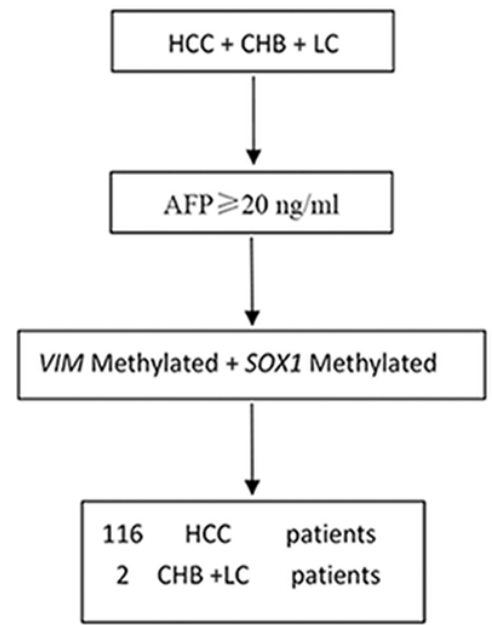

Method II

Figure 4. Diagnostic algorithms of Method I and Method II to discriminate HCC patients from CHB and LC patients.

Figure 4. When AFP was more than $20 \mathrm{ng} / \mathrm{ml}$ or at least one gene of SOX1 and VIM was methylated, the sensitivity, specificity, PPV and NPV were $88.33 \%, 72.63 \%, 89.08 \%$ and $71.13 \%$, respectively. When AFP was more than $20 \mathrm{ng} / \mathrm{ml}$ and SOX1 and VIM were both methylated, the sensitivity, specificity, PPV, and NPV were $48.33 \%, 97.89 \%, 98.31 \%$ and $42.86 \%$, respectively. From Table 7, we can conclude that Method I provides higher sensitivity than Method II $(\chi 2=68.912, p<0.001)$ and AFP alone $(\chi 2=25.960, p<0.001)$. The specificity of Method II for discriminating HCC from LC and CHB patients is higher. The correlation coefficient between AFP and VIM was 0.271 , $p<0.001$; and AFP and SOX1 was $0.186, p=0.004$. Moreover, the AUC of SOX1 and VIM methylation was significantly higher

Table 4. Univariate Logistic Regression Analysis of SOX 1 Promoter Methylation with Clinicopathological Characteristics in HCC

\begin{tabular}{lccc}
\hline SOX1 & $\begin{array}{c}\text { Tumor size } \\
>5 \mathrm{~cm}\end{array}$ & $\begin{array}{c}\text { Tumor } \\
\text { multiplicity }\end{array}$ & $\begin{array}{c}\text { TNM stage } \\
\text { III-IV }\end{array}$ \\
\hline P & 0.177 & 0.001 & 0.001 \\
OR & 1.542 & 0.208 & 4.987 \\
95\% CI & $0.822-2.892$ & $0.095-0.456$ & $2.113-11.768$ \\
\hline
\end{tabular}

OR, odds ratio; CI, confidence interval; TNM, tumor node metastasis

Table 5. Univariate Logistic Regression Analysis of VIM Promoter Methylation with Clinicopathological Characteristics in HCC

\begin{tabular}{lcccc}
\hline VIM & $\begin{array}{c}\text { Tumor size } \\
>5 \mathrm{~cm}\end{array}$ & PVTT & invasion & $\begin{array}{c}\text { TNM stage } \\
\text { III-IV }\end{array}$ \\
\hline $\mathrm{p}$ & 0.037 & 0.001 & 0.001 & 0.001 \\
OR & 2.340 & 0.006 & 33.681 & 3.978 \\
$95 \% \mathrm{CI}$ & $1.053-5.198$ & $0.001-0.040$ & $9.410-120.561$ & $1.789-8.847$ \\
\hline
\end{tabular}

PVTT, portal vein tumor thrombus; OR, odds ratio; CI, confidence interval. than that of AFP in discriminating HCC from CHB and LC patients $(0.805$ versus $0.742 ; p=0.012$ ) (Figure 5 ).

\section{Discussion}

In this study, we first demonstrated that SOX1 and VIM promoter methylation could be detected in the serum of patients with HCC, LC, CHB and in HCs. The frequency of SOX1 and

Table 6. Sensitivity, Specificity, PPV and NPV of gene promoter methylation and AFP to discriminate HCC from LC and CHB

\begin{tabular}{lcccc}
\hline Marker & $\begin{array}{c}\text { Sensitivity } \\
(\%)\end{array}$ & $\begin{array}{c}\text { Specificity } \\
(\%)\end{array}$ & PPV (\%) & NPV (\%) \\
\hline SOX1 & 72.08 & 84.21 & 92.02 & 54.42 \\
VIM & 61.67 & 83.16 & 90.24 & 46.20 \\
SOX1/VIM & 82.50 & 78.95 & 90.83 & 64.10 \\
AFP & 56.67 & 83.16 & 89.47 & 43.17 \\
\hline
\end{tabular}

AFP, alpha-fetoprotein; PPV, positive predictive value; NPV, negative predictive value.

Table 7. Diagnostic Value of Two Methods for Discriminating HCC from $\mathrm{LC}$ and $\mathrm{CHB}$

\begin{tabular}{lcccc}
\hline Marker & $\begin{array}{c}\text { Sensitivity } \\
(\%)\end{array}$ & $\begin{array}{c}\text { Specificity } \\
(\%)\end{array}$ & PPV (\%) & NPV (\%) \\
\hline $\begin{array}{l}\text { AFP/SOX1/VIM } \\
\text { Methylation(Method I) }\end{array}$ & 88.33 & 72.63 & 89.08 & 71.13 \\
$\begin{array}{l}\text { AFP+SOX1+VIM } \\
\text { Methylation(Method II) }\end{array}$ & 48.33 & 97.89 & 98.31 & 42.86 \\
\hline
\end{tabular}

AFP, alpha-fetoprotein; $\mathrm{PPV}$, positive predictive value; NPV, negative predictive value. 
VIM promoter methylation in HCC was $72.08 \%$ and $61.67 \%$, respectively, which was significantly higher than that in LC $(17.24 \%, 24.14 \%)$ and CHB $(15.15 \%, 13.64 \%)$ patients and in HCs $(4 \%, 12 \%)$. The results were consistent with previous studies that showed that the SOX1 and VIM promoters are methylated in HCC tissues [24, 33]. HBV is a major public health problem worldwide, with approximately 2 billion individuals infected and 400 million people with chronic HBV infection [39]. Previous studies have indicated that chronic hepatitis - cirrhosis - HCC is a continuous progress [40]. The results of our study showed that the frequency of SOX1 and VIM promoter methylation gradually increased from the HCs to patients with, CHB, LC and HCC. This trend may provide a simple and practical method to predict disease progression earlier.

For diagnosis, the status of serum SOX1 and VIM promoter methylation showed a higher sensitivity $(72.08 \% ; 61.67 \%)$ and specificity $(84.21 \% ; 83.16 \%)$ than that of AFP $(56.67 \%$, $83.16 \%$ ) in discriminating HCC from CHB and LC. However, the combination of SOX1 and VIM promoter methylation elevated the sensitivity to $82.50 \%$ in diagnosing HCC. Furthermore, we combined measurement of AFP level $(\geq 20)$ with the methylation of SOX1 and VIM promoters, and if there is at least one positive index, then the diagnostic ability increases to $88.33 \%$. If all the indexes are positive, then the specificity significantly improves to $97.89 \%$. The false negative rate of AFP is high, but epigenetic changes occur early and are stable, and thus, can compensate for the deficiency of AFP and increase the detection rate of HCC.

SOX1 is a member of the SOX transcript factor superfamily. Recently, the function of SOX1 promoter methylation has received more attention. It has been demonstrated that SOX1 is a tumor suppressor that interferes with $\mathrm{Wnt} / \beta$-catenin signaling in the development of HCC. Moreover, researchers have found that SOX1 is frequently downregulated in HCC cells and tissues. Furthermore, they have observed that constitutive overexpression of SOX1 can suppress cell proliferation, colony formation and invasion ability in HCC cell lines, and knockdown of SOX 1 can partially restore these functions [24]. In addition, it has also been reported that there is a significant correlation between downregulation of SOX1 expression and promoter methylation in HCC tissues. The percentage of methylation is $57.3 \%$, which is significantly higher than that of chronic hepatitis and cirrhosis tissues [32]. In addition to its function in HCC, methylation of SOX1 is more frequently associated with non-small cell lung cancer [41]. A recent study on cervical cancer found that SOX1 was frequently methylated in squamous cervical cell carcinomas, and the aberrant methylation rate is $81.5 \%$ according to a quantitative methylation-specific PCR assay [42]. Vimentin is a marker of mesenchymal cells that is associated with cell adhesion, cytoplasmic microtubule assembly, and cytoskeleton remodeling [29]. Furthermore, previous studies have indicated that vimentin participates in epithelial-mesenchymal transition (EMT). EMT is a process in which tumor cells

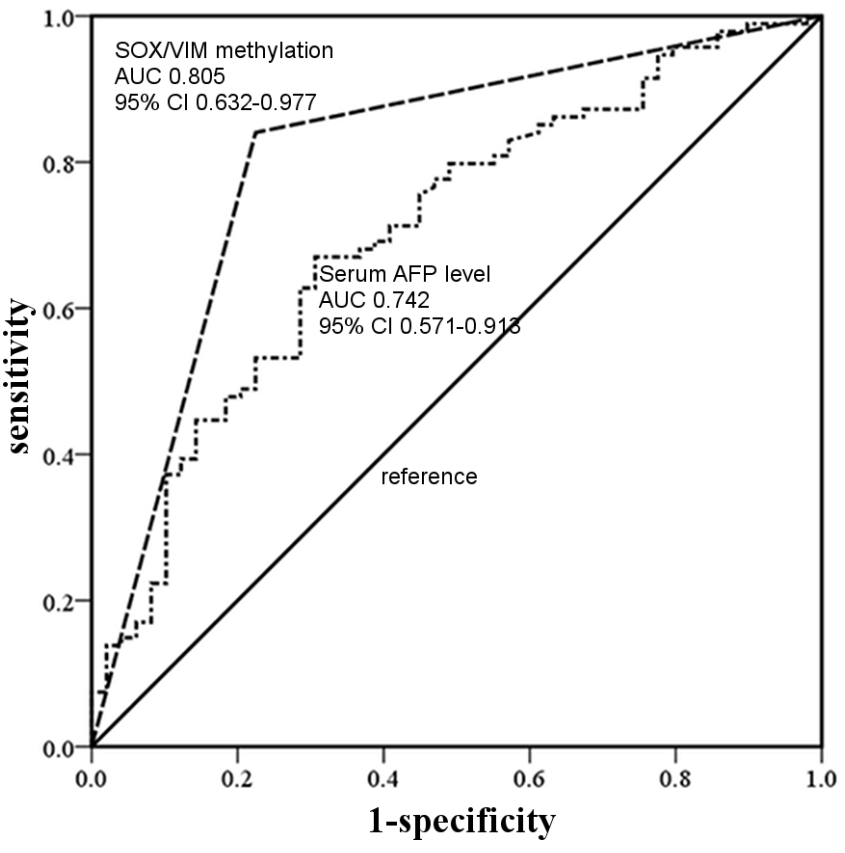

Figure 5. Receiver operating characteristic curves (ROCs) of serum AFP level $\geq 20 \mathrm{ng} / \mathrm{ml}$ and the methylation of $S O X 1$ and VIM promoters in discriminating $\mathrm{HCC}$ from $\mathrm{CHB}$ and LC.

lose the characteristic polarity of epithelial cells and acquire the characteristics of stroma cells. EMT is a critical event in invasion and metastasis of malignant cells [43, 44]. From our study, we evaluated whether promoter methylation of serum SOX1 and VIM was associated with clinicopathological parameters in HCC patients. We found that SOX1 promoter methylation was associated with multiple tumors and TNM stage (III-IV). VIM promoter methylation was highly associated with PVTT, TNM stage (III-IV), tumor size $(>5 \mathrm{~cm}$ ) and vascular invasion. Promoter methylation of SOX1 and VIM may affect the expression of other related genes, which may lead to clinicopathological changes in HCC. Patients with portal vein tumor thrombus and metastasis showed an elevated percentage of serum VIM promoter methylation ( $p=0.006, p=0.003)$. This indicated that VIM promoter methylation was correlated with HCC progression, migration and proliferation, although the molecular mechanisms were unclear. Univariate logistic regression analysis indicated that risk factors of VIM promoter methylation were PVTT $(\mathrm{OR}=0.006)$ and metastasis $(\mathrm{OR}=33.681)$. Based on the results, we propose that the combination of serum SOX1 and VIM promoter methylation might be a useful predictor of HCC progression.

The present study has some limitations. First, the observations of SOX1 and VIM promoter methylation were from a small number of patients within a single site. More studies with a larger number of HCC patients from multiple locations are expected in the future. Second, we need long-term follow- 
up observations to reveal the prognostic value of $S O X 1$ and VIM methylation in HCC patients. Third, we did not quantify the mRNA and protein levels of SOX1 and VIM in the serum and tissue of HCC patients. We will perform further studies to detect the relationship between SOX1 and VIM expression and promoter methylation in HCC patients. However, the main aim of the present study was to confirm whether SOX1 and VIM promoter methylation were present in the serum of HCC patients and whether they could function as biomarkers for HCC diagnosis.

In summary, we primarily determined the status of SOX1 and VIM promoter methylation in serum and evaluated the potential value of serum SOX1 and VIM promoter methylation in the diagnosis of HCC. We report that serum SOX1 and VIM methylation showed a higher sensitivity than AFP alone for the diagnosis of HCC, suggesting that serum SOX1 and VIM promoter methylation might be potential noninvasive biomarkers for HCC. Further studies are needed to validate the mechanism and assess the clinical value.

Acknowledgements: This work was supported by grants from the Key Project of Chinese Ministry of Science and Technology (2012ZX10002007, 2013ZX10002001), and National Natural Science Foundation of China (81371832).

\section{References}

[1] BOSETTI C, TURATI F, LAVECCHIA C. Hepatocellular carcinoma epidemiology. Best Pract Res Clin Gastroenterol 2014; 28: 753-770. https://doi.org/10.1016/j.bpg.2014.08.007

[2] BEN ARI Z, WEITZMAN E, SAFRAN M. Oncogenic viruses and hepatocellular carcinoma. Clin Liver Dis 2015; 19: 341-360. https://doi.org/10.1016/j.cld.2015.01.006

[3] ROEB E. Hepatocellular carcinoma - current aspects of screening, surveillance and therapeutic strategies (revised EASL-EORTC recommendations). Zentralbl Chir 2014; 139: 175-183.

[4] FERRIN G, AGUILAR-MELERO P, RODRIGUEZ-PERALVAREZ M, MONTERO-ALVAREZ JL, DE LA MATA M. Biomarkers for hepatocellular carcinoma: diagnostic and therapeutic utility. Hepat Med 2015; 7: 1-10. https://doi. org/10.2147/HMER.S50161

[5] CHEDID A, CHEJFEC G, EICHORST M, VILLAMIL F, TERG R et al. Antigenic markers of hepatocellular carcinoma. Cancer 1990; 65: 84-87. https:// doi.org/10.1002/1097-0142(19900101)65:1<84::AIDCNCR2820650118>3.0.CO;2-D

[6] NAYLOR S. Biomarkers: current perspectives and future prospects. Expert Rev Mol Diagn 2003; 3: 525-529. https:// doi.org/10.1586/14737159.3.5.525

[7] MAYEUX R. Biomarkers: potential uses and limitations. NeuroRx 2004; 1: 182-188. https://doi.org/10.1602/neurorx.1.2.182

[8] OGINO S, LOCHHEAD P, CHAN AT, NISHIHARA R, CHO $\mathrm{E}$ et al. Molecular pathological epidemiology of epigenetics: emerging integrative science to analyze environment, host, and disease. Mod Pathol 2013; 26: 465-484. https://doi. org/10.1038/modpathol.2012.214

[9] ALIX-PANABIERES C, PANTEL K. Clinical Applications of Circulating Tumor Cells and Circulating Tumor DNA as Liquid Biopsy. Cancer Discov 2016; 6: 479-491. https://doi. org/10.1158/2159-8290.CD-15-1483

[10] GALL TM, FRAMPTON AE, KRELL J, HABIB NA, CASTELLANO L et al. Cell-free DNA for the detection of pancreatic, liver and upper gastrointestinal cancers: has progress been made? Future Oncol 2013; 9: 1861-1869. https://doi. org/10.2217/fon.13.152

[11] FUKUSHIGE S, HORII A. DNA methylation in cancer: a gene silencing mechanism and the clinical potential of its biomarkers. Tohoku J Exp Med 2013; 229: 173-185. https:// doi.org/10.1620/tjem.229.173

[12] HUANG W, LI T, YANG W, CHAI X, CHEN K et al. Analysis of DNA methylation in plasma for monitoring hepatocarcinogenesis. Genet Test Mol Biomarkers 2015; 19: 295-302. https:// doi.org/10.1089/gtmb.2014.0292

[13] WANG J, QIN Y, LI B, SUN Z, YANG B. Detection of aberrant promoter methylation of GSTP1 in the tumor and serum of Chinese human primary hepatocellular carcinoma patients. Clin Biochem 2006; 39: 344-348. https://doi.org/10.1016/j. clinbiochem.2006.01.008

[14] RAMZY II, OMRAN DA, HAMAD O, SHAKER O, ABBOUD A. Evaluation of serum LINE-1 hypomethylation as a prognostic marker for hepatocellular carcinoma. Arab J Gastroenterol 2011; 12: 139-142. https://doi.org/10.1016/j. ajg.2011.07.002

[15] NISHIDA N, ARIZUMI T, TAKITA M, NAGAI T, KITAI $S$ et al. Quantification of tumor DNA in serum and vascular invasion of human hepatocellular carcinoma. Oncology 2013; 84 Suppl 1: 82-87. https://doi.org/10.1159/000345895

[16] HUANG ZH, HU Y, HUA D, WU YY, SONG MX et al. Quantitative analysis of multiple methylated genes in plasma for the diagnosis and prognosis of hepatocellular carcinoma. Exp Mol Pathol 2011; 91: 702-707. https://doi.org/10.1016/j. yexmp.2011.08.004

[17] ESTELLER M, SPARKS A, TOYOTA M, SANCHEZCESPEDES M, CAPELLA G et al. Analysis of adenomatous polyposis coli promoter hypermethylation in human cancer. Cancer Res 2000; 60: 4366-4371.

[18] HERMAN JG, BAYLIN SB. Gene silencing in cancer in association with promoter hypermethylation. N Engl J Med 2003; 349: 2042-2054. https://doi.org/10.1056/NEJMra023075

[19] HERMAN JG, MERLO A, MAO L, LAPIDUS RG, ISSA JP et al. Inactivation of the CDKN2/p16/MTS1 gene is frequently associated with aberrant DNA methylation in all common human cancers. Cancer Res 1995; 55: 4525-4530.

[20] YANG B, GUO M, HERMAN JG, CLARK DP. Aberrant promoter methylation profiles of tumor suppressor genes in hepatocellular carcinoma. Am J Pathol 2003; 163: 1101-1107. https://doi.org/10.1016/S0002-9440(10)63469-4

[21] SCHAGDARSURENGIN U, WILKENS L, STEINEMANN D, FLEMMING P, KREIPE HH et al. Frequent epigenetic inactivation of the RASSF1A gene in hepatocellular carcinoma. Oncogene 2003; 22: 1866-1871. https://doi.org/10.1038/sj.onc.1206338 
[22] CHEW LJ, GALLO V. The Yin and Yang of Sox proteins: Activation and repression in development and disease. J Neurosci Res 2009; 87: 3277-3287. https://doi.org/10.1002/ inr.22128

[23] KAN L, ISRASENA N, ZHANG Z, HU M, ZHAO LR et al. Sox1 acts through multiple independent pathways to promote neurogenesis. Dev Biol 2004; 269: 580-594. https://doi. org/10.1016/j.ydbio.2004.02.005

[24] TSAO CM, YAN MD, SHIH YL, YU PN, KUO CC et al. SOX1 functions as a tumor suppressor by antagonizing the WNT/ beta-catenin signaling pathway in hepatocellular carcinoma. Hepatology 2012; 56: 2277-2287. https://doi.org/10.1002/ hep. 25933

[25] FUCHS E, WEBER K. Intermediate filaments: structure, dynamics, function, and disease. Annu Rev Biochem 1994; 63: 345-382. https://doi.org/10.1146/annurev.bi.63.070194.002021

[26] JUNG S, YI L, KIM J, JEONG D, OH T et al. The role of vimentin as a methylation biomarker for early diagnosis of cervical cancer. Mol Cells 2011; 31: 405-411. https://doi.org/10.1007/ s10059-011-0229-X

[27] LAI HC, LIN YW, HUANG TH, YAN P, HUANG RL et al. Identification of novel DNA methylation markers in cervical cancer. Int J Cancer 2008; 123: 161-167. https://doi. org/10.1002/ijc.23519

[28] ZHAO Y, ZHOU H, MA K, SUN J, FENG X et al. Abnormal methylation of seven genes and their associations with clinical characteristics in early stage non-small cell lung cancer. Oncol Lett 2013; 5: 1211-1218.

[29] ZHOU YF, XU W, WANG X, SUN JS, XIANG JJ et al. Negative methylation status of vimentin predicts improved prognosis in pancreatic carcinoma. World J Gastroenterol 2014; 20: 13172-13177. https://doi.org/10.3748/wjg.v20. $\underline{\mathrm{i} 36.13172}$

[30] SU HY, LAI HC, LIN YW, CHOU YC, LIU CY et al. An epigenetic marker panel for screening and prognostic prediction of ovarian cancer. Int J Cancer 2009; 124: 387-393. https:// doi.org/10.1002/ijc.23957

[31] SHIRAHATA A, HIBI K. Serum vimentin methylation as a potential marker for colorectal cancer. Anticancer Res 2014; 34: 4121-4125.

[32] SHIH YL, HSIEH CB, YAN MD, TSAO CM, HSIEH TY et al. Frequent concomitant epigenetic silencing of SOX1 and secreted frizzled-related proteins (SFRPs) in human hepatocellular carcinoma. J Gastroenterol Hepatol 2013; 28 : 551-559. https://doi.org/10.1111/jgh.12078
[33] KITAMURA Y, SHIRAHATA A, SAKURABA K, GOTO T, MIZUKAMI $\mathrm{H}$ et al. Aberrant methylation of the Vimentin gene in hepatocellular carcinoma. Anticancer Res 2011; 31: 1289-1291.

[34] BRUIX J, SHERMAN M. Management of hepatocellular carcinoma: an update. Hepatology 2011; 53: 1020-1022. https:// doi.org/10.1002/hep. 24199

[35] LOK AS, MCMAHON BJ. Chronic hepatitis B: update 2009. Hepatology 2009; 50: 661-662. https://doi.org/10.1002/ $\underline{\text { hep. } 23190}$

[36] LU H, HUANG S, ZHANG X, WANG D, ZHANG X et al. DNA methylation analysis of SFRP2, GATA4/5, NDRG4 and VIM for the detection of colorectal cancer in fecal DNA. Oncol Lett 2014; 8: 1751-1756. https://doi.org/10.3892/ol.2014.2413

[37] DOU CY, FAN YC, CAO CJ, YANG Y, WANG K. Sera DNA Methylation of CDH1, DNMT3b and ESR1 Promoters as Biomarker for the Early Diagnosis of Hepatitis B Virus-Related Hepatocellular Carcinoma. Dig Dis Sci 2016; 61: 1130-1138. https://doi.org/10.1007/s10620-015-3975-3

[38] DENG QK, LEI YG, LIN YL, MA JG, LI WP. Prognostic Value of Protocadherin10 (PCDH10) Methylation in Serum of Prostate Cancer Patients. Med Sci Monit 2016; 22: 516-521. https://doi.org/10.12659/MSM.897179

[39] KANG L, PAN J, WU J, HU J, SUN Q et al. Anti-HBV Drugs: Progress, Unmet Needs, and New Hope. Viruses 2015; 7: 4960-4977. https://doi.org/10.3390/v7092854

[40] BRUIX J, SHERMAN M. Management of hepatocellular carcinoma. Hepatology 2005; 42: 1208-1236. https://doi. org/10.1002/hep.20933

[41] VURAL B, CHEN LC, SAIP P, CHEN YT, USTUNER Z et al. Frequency of SOX Group B (SOX1, 2, 3) and ZIC2 antibodies in Turkish patients with small cell lung carcinoma and their correlation with clinical parameters. Cancer 2005; 103: 2575-2583. https://doi.org/10.1002/cncr.21088

[42] LAI HC, LIN YW, HUANG TH, YAN P, HUANG RL et al. Identification of novel DNA methylation markers in cervical cancer. Int J Cancer 2008; 123: 161-167. https://doi. org/10.1002/ijc.23519

[43] HUBER MA, KRAUT N, BEUG H. Molecular requirements for epithelial-mesenchymal transition during tumor progression. Curr Opin Cell Biol 2005; 17: 548-558. https://doi. org/10.1016/j.ceb.2005.08.001

[44] IVASKA J. Vimentin: Central hub in EMT induction? Small GTPases 2011; 2: 51-53. https://doi.org/10.4161/ sgtp.2.1.15114 